the bodies in one slide out of several examined. On the other hand, this was by no means their invariable experience, while they once recovered the bodies from broth into which a piece of the liver of an ox or cow had been placed. This would appear effectually to dispose of the idea that they are derived from any part of the skin, unless some contamination had occurred. ${ }^{2}$ The same remark applies to their successful inoculations of rabbits.

I asked Dr. Mâloüf to send me some more blood films, and he forwarded ten, all unfortunately taken from one of the urticarial wheals and numbered in the order in which they had been taken. In none of them were $\mathrm{X}$ bodies found. The previous blood films had been made from finger blood. I now sent Dr. Mâloüf two tubes of Nicolle's blood agar and several tubes containing the 1 per cent. sodium citrate solution employed by Horrocks and Howell, and requested him to inoculate these tubes with appropriate quantities of blood taken from the finger as at first. This he kindly did, and I incubated the inoculated media at or about $22^{\circ} \mathrm{O}$. The tubes were examined daily for five days, care being taken to secure the blood sediment from the citrate tubes. Unfortunately coccal or bacterial contamination, apparently of cutaneous origin, eventually made its appearance in every one of the tubes, and at no time were any $X$ bodies found. I tried hard to get the patient to visit the laboratories, but in vain; and before Dr. Mâloüf could obtain other films or make other blood cultures she left for Kamlin on the Blue Nile. Hence, much to my regret, I was unable to pursue the case further or to confirm the findings of Horrocks and Howell in culture media, or to repeat and extend their inoculation experiments.

Although one cannot express any opinion on these curious bodies their occurrence in the Sudan is certainly interesting, as is the fact that they were found in a case unassociated with fever, but suffering from a recurrent or intermittent urticaria. I am indebted to Mr. George Buchanan, our senior laboratory assistant, for the careful drawing illustrating the main types present.

Khartoum.

\section{SOME CASES ILLUSTRATING THE EFFECTS OF THE HYPER无MIA TREATMENT BY ELASTIC BANDAGE ON UN- UNITED FRACTURES.}

BY ARTHUR E. BARKER, F.R.C.S. ENG., SURGEON TO UNIVERSITY COLLEG HOSPITAL, AND CONSULTING
SURGEON TO THE QUEEN ALEXANDRA MILITARY Hospital, MILLBANK, 8.w.

TROUBLESOME cases of ununited fracture are constantly occurring in surgical practice and tax our resources to the utmost in bringing about their repair. The condition appear to be met with after any kind of fracture of the long bones, from the most simple and limited to the most extensive comminuted and compound varieties. The various causes are fairly well recognised now and need not be alluded to, the object of this communication being merely to report cases in which a very simple method of treatment was followed by the best results where other more serious measures had failed. The treatment is not new, but though it has been in favour with some for many years it does not appear to have as yet gained for itself that place in ordinary surgical procedure to which it is entitled.

The method of inducing union in ununited fractures by engorging the parts around by bandaging above and below the lesion appears to have been first proposed and practised by Mr. Thom is of Liverpool many years ago. This is pointed out by Bier in his valuable treatise on the uses of artificial hyperæmia in surgery, which has done so much to enlarge our views on the processes of repair in many ailments. But so far the practical use of hyperæmia, as applied to ununited fractures, does not appear to have become general, as remarked above.

2 Mr. George Buchanan, however, drew my attention to the fact that some of the forms were present on the slide beyond what one may call the "commercement end" of the bloor film. This rather suggests that they may have been derived from the surface of the skin, especially as, in ali probability, the slide was pressed down upon the finger in order to take up the drop, and not merely allowed to come in contact with the latter.
When a simple, say transverse, fracture of the tibia (e.g., Case 2), put up and maintained in perfect position, is found at the end of six or eight weeks quite ununited, several other facts about the limb may usually be noticed as well. It is, of course, flabby, and more or less wasted from disuse ; it is colder than its fellow, and, as a rule, the skin is paler. The necessity for complete immobilisation is the cause, and prevents us from employing massage or any of the usual means for keeping up the normal nutrition of the limb. This may, of course, in exceptional cases, have been further impaired by needlessly firm bandaging. But apart from this mere disuse produces a greater or less amount of anæmia in the injured area, although at the first there is a certain degree of traumatic hyperæmia, the first step in the process of repair.

lt seems, therefore, quite a common-sense measure to create by mechanical means an increased flow of blood through the part. This was often done in earlier days by forcibly rubbing the bones together and so reproducing a traumatic hyperæmia. But the objections to this were obvious, the chief one being the difficulty of replacing the bones in good position. The use of the elastic bandage is now found to be equally efficacious or more so. In the cases below it was applied lightly over the limb below to within a couple of inches of the fracture and more firmly above downwards to within the same distance of the lesion. The only difficulty met with is in producing the necessary amount of engorgement without interfering with circulation in the deeper parts. The upper bandage had often to be readjusted more than once to obtain the blue-pink flush without pain, which should always be present. Ány pain or absence of circulation in the interval between the bandages was always a reason for the removal of the upper one. The engorgement was kept up about two hours morning and evening, and in the intervals the whole limb was wrapped up in warm wool.

In the last case in our group, in which necrosis of the ends of the bone had taken place as the result of the laceration of the soft parts and the periosteum by the injury, another effect of the engorgement was in play. The sinus left after removal of the sequestra was presumably more or less infected, although the temperature for weeks bad been quite normal. Here the first effect of the constriction hyperæmia was always to produce an increased flow of serum, and it is fair to assume that any organisms present were mechanically carried out of the sinus. But besides this, the germicidal effects of the healthy serum resulted soon in a perfect cleaning of the granulating track. The net result was a rapid healing of the whole wound. The gradual formation of abundant callus could be followed by skiagrams after this until union was sound. Since then active exercise has been encouraged in every way, and the limb has been massaged to improve nutrition and get rid of the stiffness naturally following such prolonged disuse.

It will be noted that in the first case recorded here two attempts to secure union by wiring had failed, and though abundance of time had elapsed after the last operation to allow of the formations of callus no repair had taken place. It was only when the hyperæmia had been kept up for some time that this result was obtained and union became solid.

The last case was a particularly serious one. For it was the patient's right arm, and a second wiring was not considered desirable in view of a state of ulceration, necrosis, and sinus remaining after the original injury. The removal of the sequestra besides left a gap between the bones and a granulating cavity. In this case all that was done was to place a thick rod of aluminium within the medullary cavity of both ends so as to keep them in a straight line. The two pieces were pushed together over this and nothing further was done to hold them together. A small gauze drain was inserted down to the line of fracture and the wound was partially closed. What remained healed with remarkable rapidity under the increased hyperæmia induced by the bandage and our radiograms showed how quickly callus began to form after this. It may be suggested that all this would have taken place without the bandage. Perhaps it might. But the fact remains that no trace of repair of the bone could be made out until the hyperæmia had been in full swing for 10 for 12 days, when our patience was nearly exhausted. Moreover, the same result was obtained in the two practically simple fractures, Cases 2 and 3 , which had failed to unite under conditions which 
were more than usually favourable. The bandage was applied when surgeon and patient were beginning to lose heart : the effect was rapid union.

CASE 1.-The patient, a man, aged 37 years, was admitted on Nov. 4th, 1905, for a compound comminuted fracture of the right humerus at the junction of the lower and middle third with a subcoracoid dislocation. There was a wound on the inner side of the arm from which much blood was oozing. The main line of fracture ran from above downwards, forwards, and outwards. Another plane of fracture ran downwards and inwards, cutting the other plane at about its upper third and separating a triangular fragment from the shaft. The lower pointed end of this separate piece was broken off by a third line of fracture. Under chloroform the dislocation was easily reduced and the rather pointed ends of the main fragments were wired together and some small fragments and débris removed. The incision which had been made through the fracture wound was partly stitched up and the rest drained with aseptic gauze. The first couple of days a large quantity of clear brownish discharge came away followed by a fall of temperature, which had been high. After this the wound steadily closed and he left hospital nearly healed, the arm being still in splints. Healing was complete at the end of December.

On March 5th, 1906, he was readmitted looking well and wound soundly healed. But the fracture was ununited, and a radiogram showed much displacement and that the triangular fragment mentioned in the first notes had slipped in between the end of the upper and lower main portions of the humerus.

On March 8th I opened up the old scar, removed the wire and the intervening loose but still living triangular fragment, and "scarfed" the ends of the main upper and lower bones, and united them with two wires in good position. The wound did very well and the patient went home on March 31st.

On Oct. 24th the patient was readmitted, and it was thought that the union was sound. It was also found that the head of the humerus had again slipped out and lay under the coracoid. During scme attempts to reduce the dislocation, which failed owing to firm adhesions, the fracture was found to be ununited. The head of the bone was resected and the arm put up straight. This wound healed quite satisfactorily, but the fracture did not unite for some months. The Bier's bandage was then applied when he came up daily during a holiday which I had, and on my return I found it firmly united.

CASE 2.-A man, aged 56 years, was sent to me a year ago for transverse fracture of the tibia. This had occurred in the hunting field from the kick of a neighbour's horse and was compound. He had been admirably dressed and the limb put up in splints by Dr. H. Fraser of Harpenden. I had little to do but to cleanse the wound, cover it with boric lint, and put the leg in side splints. The wound healed without reaction and the splints were, at the end of eight weeks, put into a Croft's plaster apparatus. Union had not taken place when the patient went to Brighton. I requested the surgeon under whose care I placed him to remove the Croft in a week or two and report progress. This he did and told me there was no union. I then asked him to use Bier's bandage and report further. This he did a few weeks later, informing me that the tibia was firmly healed.

CASE 3.-The patient, a man, aged 44 years, was admitted for transverse fracture of the left humerus a little above the middle, which was ununited. He had sustained the fracture three and a half months before from a fall on the shoulder. The arm was in splints until a week before he came in and was then found, after passive movement, to be ununited. The ends of the bone were found to be in good position, but there was very little surrounding callus. On the next day I applied Bier's bandage above and below the fracture for about one hour each day and later for one and a half hours twice a day. On April 10th the note is that "union seems to have taken place." The hyperæmia was continued as before. On April 29th the union was quite sound and the patient went home.

CASE 4.-A young man, aged 21 years, fell from his bicycle in Suffolk on July $24 \mathrm{th}, 1910$, and sustained a bad transverse fracture of the right humerus with much laceration of periosteum and soft parts, and with extensive subcutaneous and intramuscular bleeding. He was put up with an aseptic dressing and splint and sent up the next day to University College Hospital. Position was good, but it was doubtful whether asepsis had been secured. There was an open wound on the front and inner side of the middle of the arm, which, after the usual cleansing and painting with tincture of iodine, was enlarged. Much laceration and blood clot were found and a transverse fracture. This was wired firmly in excellent position and the wound was closed. It was necessary to let go a couple of stitches a few days later as there was a considerable amount of altered blood clot and turbid serous effusion and rise of temperature. After this the temperature fell to normal and remained so until the end of the case. The wound, however, continued to secrete and the bone failed to unite. When I returned from my summer holiday it was still without callus and there was a small sinus. A radiogram showed that a small portion of both ends had necrosed. The wound was now opened up on Sept. 29th, 1910, sufficiently to remove the sequestra and the loosened wire. A rod of aluminium was then placed between the two ends in the medullary cavity to keep the fragments in line, but they were not further secured by wire, being simply forced together over the metal rod. At the end of ten days, when the stitches had been removed, the elastic bandage was applied for two hours morning and evening. The first effect was to increase the flow of serum from the sinus and to help to its rapid closure. Soon after the borles began to knit and a skiagram showed the formation of callus. Union was soon firm and the patient is now exercising his arm and is having massage to remove the stiffness and muscular atrophy following disuse. The radiograms now show a fair amount of callus which is on the increase; also that the aluminium rod has gravitated downwards somewhat, and, what I cannot explain, has escaped from the medullary cavity of the lower fragment.

To sum up, it may be accepted as fairly certain that, excepting the interposition of fragments of detached bone, of muscles or tendons, or of stripping of periosteum, the chief cause of delayed or completely arrested union of fractured bones is lack of proper circulation in the area injured. This may be due to rupture of the arteries supplying the bones, to over-tight bandages when the splints are applied, or, above all, to disuse. If the vascular supply is damaged it is plain that we cannot repair the condition. But we can further impair the proper blood-supply by improper bandaging. This is aroidable. As to disuse, as long as the fracture is insecure it is difficult to make any use of the muscles of the limb. If we could it is probable that such fractures would rarely fail to unite. We know that broken ribs, which are always in a state of movement, bardly ever remain ununited. I have never seen a case or read of one. When then for any of the last causes mentioned repair has not taken place, it is natural to turn to mechanical measures to increase the hyperæmia of the parts involved. In the past we know that this has been done, either by forcibly rubbing the fractured ends together to excite a fresh traumatic hyperæmia, or by pegging the bones with ivory nails or by massage. These measures have succeeded in many cases and failed in others, in the last case often on account of suppuration. It is only claimed for the elastic bandage that it produces a greater vascularity of all the parts involved easily and without risk if properly done.

The question how long it should be kept up is variously answered. In my own experience all the effects desired have been obtained by the use of the bandage for about two hours morning and evening.

Two of these cases have been shown at the Medical Society.

Harley-street, W.

Tenth Congress of the German OrthoPadil Surakry Society. - The Tenth Congress of the Deutsche Gesellschaft für Orthopädische Cnirurgie will take place as usual on the Tuesday of Easter week, April 18th, the day before the assembly of the German Surgical Society, in Langenbeckhaus, Ziegelstrasse, 10 and 11, Berlin. The hour for the opening of the Congress is 9 A M The President for 1911 is Dr. H. Hoeftman, Körigsberg i.Pr. 